\title{
Structural investigation of sparfloxacin drug using mass spec-trometry and MNDO semi-empirical molecular orbital calcu-lations
}

\author{
Mamoun S.M. Abd El-Kareem ${ }^{1}$ *, M. El-desawy ${ }^{1}$, M. F. Hawash ${ }^{1}$, M. A. Fahmey ${ }^{1}$ \\ ${ }^{1}$ Molecular and atomic physics unit., Experimental Nuclear Physics Dept., Nuclear Research Centre, \\ Egyptian Atomic Energy Authority, Inshas, Cairo, Egypt \\ *Corresponding author_E-mail: mamoun_sarhan@yahoo.com
}

\begin{abstract}
Sparfloxacin is a broad spectrum antibacterial fluoroquinolone against some microorganisms including gram-positive and gramnegative bacteria and exhibits moderate activity against anaerobes and mycobacteria. Sparfloxacin is well tolerated and the intake of food has no adverse effect on the pharmacokinetic features (Blondeau 1999, Stahlmann et al. 1998). For the medical important of this drug author have been study its structure by recording and investigate its electron ionization (EI) mass spectra at different electron energies 70 and $15 \mathrm{eV}$. Also, the chemical ionization (CI) mass spectrum has been recorded and investigated. The main fragmentation processes in EI and CI have elucidated and discussed. The main fragment ions in EI mass spectra are $\left[\mathrm{M}_{-} \mathrm{C}_{4} \mathrm{H}_{8} \mathrm{~N}\right]^{+}$and fragment $\left[\mathrm{M}-\mathrm{C}_{4} \mathrm{H}_{8} \mathrm{~N}-\mathrm{CO}_{2}\right]^{+}$, while $\left[\mathrm{MH}-\mathrm{CO}_{2}\right]^{+}$ion are the most fragment ion in CI mass spectrum. On the other hand, the molecular structure optimization of sparfloxacin was calculated using the modified neglect of diatomic overlap (MNDO) semi-empirical molecular orbital method. Also, the thermochemical data such as heat of formations, total energy, ionization energy, electron affinity and dipole moment have been calculated and discussed.
\end{abstract}

Keywords: Sparfloxacin; Mass Spectrometry and Semi-Empirical Molecular Orbital Calculations.

\section{Introduction}

Heterocyclic compounds have different types of pharmacological properties (Singh et al.1992, David et al. 1972). Several quinolones like Ciprofloxacin, Pefloxacin, Levofloxacin, Sparfloxacin are released in the clinical world. Synthesis of various substituted quinolone intermediate compounds is of current interest because of their therapeutically potential in the area of human and animal health such as antibacterial (Libel et al. 1988, Menon et al. 1977, Christos et al.2003).

Sparfloxacin [5-amino-1-cyclopropyl-7-(cis-3, 5-dimethyl-1- piperazinyl)-6, 8-difluoro-1, 4-dihydro-4-oxo-3-quinoline carboxylic acid]. (Molecular formula: $\mathrm{C}_{19} \mathrm{H}_{22} \mathrm{~F}_{2} \mathrm{~N}_{4} \mathrm{O}_{3}$, Molecular weight: 392 ) is a third generation fluoroquinolones which is the one of the most important and successful classes of manmade antibacterial used in the treatment of lung infection, urinary tract infection and cutaneous allergy. Sparfloxacin is receiving attention due to its broad spectrum activity, potency and excellent pharmacokinetic profiles (Jain et al.2002, Marona et al. 2001, Faria et al. 2006)

Different analytical methods have been reported for quantitative determination of Sparfloxacin in pharmaceutical preparation like DC polarography (Jain et al.2002), HPLC (Maronaab et al.1999, Ziyu et al. 2017, CaO et al.2001), and capillary zone electrophoresis (Sun\& Wu 1999, Fierrens et al.2000). Spectrophotometric methods have also been reported based on the indirect determination of Sparfloxacin with N- bromosuccinimide (Aska et al. 2007), ternary complex with Pd(II) and eosin (El-Didamony 2007) and UV-Spectrophotometry (Chowdary et al. 1997, Vegad et al. 2017).
These methods are based on intrinsic fluorescence property or complexation reaction with aluminum chloride (Rizk et al. 2000), derivatization of Sparfloxacin with hydrobromic acid (Du et al.2000), hydrochloric acid (Jasmin et al. 2012) and phosphine (Urszl et al. 2015). Ce (IV) is a well-known oxidizing agent. It is used for the indirect determination of a number of drugs (Sultan et al. 1986, Koukli et al. 1989, Martínez et al.1992, Perez-Rinz et al. 1993, Alwarthan 1995, Aly et al. 1998, Adegoke et al. 2010).Also, fourier transform infrared and ultraviolet-visible spectroscopic characterization of sparfloxacin have been investigated (Mahendra et al. 2015).

It is very important to study the chemistry and reactivity of Sparfloxacin drug because of its importance in medical felid. Knowledge obtained from the investigation of its mass spectra using different ionization techniques of the neutral drug is very important to understand the chemical process that is shared in biological activity. It is difficult to establish the exact major fragmentation pathway in EI using conventional MS. With the combination of the EI and CI techniques and the data obtained from the MO calculation, it is possible to understand that process and explain the following topics:

1) Stability of this drug under EI-MS fragmentation in gas phase.

2) Prediction of the primary site of fragmentation using EI and CI techniques, which was used to characterize the structure of this drug.

3) Understanding how calculated thermochemical date be useful in expected the stability and reactivity of the studied drug and confirmed the correct fragmentation pathway. 
So, the present work was carried out to study and investigate Sparfloxacin structure using its mass spectra obtained using electron and chemical ionization (EI and CI) techniques and confirm the fragmentation process under the two ionization techniques using the optimization data obtained by semi-empirical MNDO method, this includes:

a) Ionization energies (IE's) of these molecules

b) Heats of formation of neutral $(\Delta \mathrm{Hf}(\mathrm{M}))$ and ionized molecules $(\Delta \mathrm{Hf}(\mathrm{M})+\bullet)$.

c) Bond length and charge distribution of the compound under investigation in neutral and charged states.

\section{Experimental}

The EI and CI mass spectra of Sparfloxacin were recorded using Finnigan Focus gas chromatograph coupled directly to a DSQ single quadrupole mass spectrometer (ThermoScintific, CA, USA) with electron multiplier detector equipped with Xcaliuber Ver.1.4 data system located at atomic and molecular physics unit, nuclear research center, Egyptian atomic energy authority. The direct insertion probe (DIP) for solid material was used to introduce the sample directly to the MS.

In the EI measurements the ion source temperature was maintained at $150{ }^{\circ} \mathrm{C}$. The EI mass spectra were recorded at two electron energies, 15 and $70 \mathrm{eV}$. The probe temperature program for the EI measurements was as follows:

Initial temperature $=60{ }^{\circ} \mathrm{C}$ then hold for 1 minute and ramping with $50{ }^{\circ} \mathrm{C} / \mathrm{min}$ to $250{ }^{\circ} \mathrm{C}$ then hold for 5 minutes.

In the CI mode of operation the ion source temperature was maintained at $130{ }^{\circ} \mathrm{C}$ and methane as a reagent gas. The CI mass spectra were recorded at $70 \mathrm{eV}$ electron energy.

The probe temperature program for the $\mathrm{CI}$ measurements was as follows:

Initial temperature was $70{ }^{\circ} \mathrm{C}$. for $60 \mathrm{sec}$. Ramp rate $50{ }^{\circ} \mathrm{C} . / \mathrm{min}$. Final temperature $250{ }^{\circ} \mathrm{C}$. for $100 \mathrm{sec}$.

\section{Theoretical calculations}

The geometry of Sparfloxacin has been optimized based on semiempirical calculations, using the molecular modeling program Hyperchem7.5 (W.Thiel 2003, HyperChemTM, Release 7.5 Pro 2002). Semi-empirical calculations were carried out using the routine MNDO and Polak-Ribiere conjugated gradient algorithm. For the optimized structure of the neutral and cation states, geometry optimization mode were carried to give molecular properties including heat of formation, dipole moment, atom charges, total energy, binding energy, electron energy and nuclear energy.

\section{Results and discussion}

a) Mass spectra and Ionization processes of Sparfloxacin using EI technique

The numbering system and the chemical structure of Sparfloxacin are shown in figure 1. While the EI mass spectra of Sparfloxacin at 70 and $15 \mathrm{eV}$ are shown in figures 2-3.Also, the CI mass spectrum of Sparfloxacin are shown in figure 7.<smiles>CC1CN(c2c(F)c(N)c3c(=O)c(C(=O)O)cn(C4CC4)c3c2F)CC(C)N1</smiles>

(B)

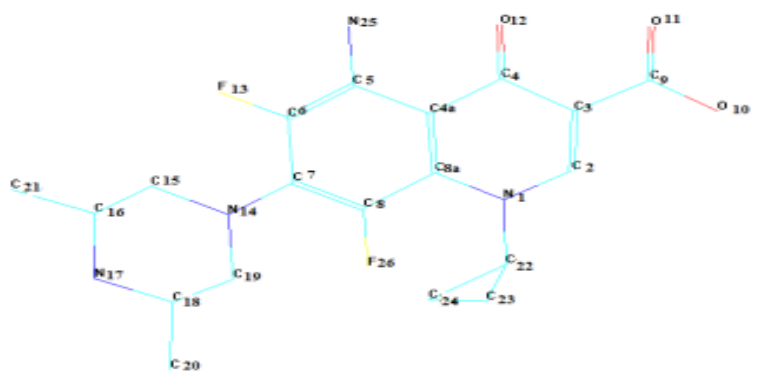

Fig. 1: (A) the Numbering System, (B) Chemical Structure of Sparfloxacin.

The experimental results are obtained in the form of mass spectra for Sparfloxacin compound using EI and CI techniques. The measurements include the EI mass spectra at two different electron energy values ( 70 and $15 \mathrm{eV}$ ) while the CI mass spectra have been obtained using methane as a reagent gas at $70 \mathrm{eV}$ only.

In this work, one can discuss the mass spectral behaviors of studied compound using the two techniques. The fragmentation pathways of the main fragment ions formed from molecular ion at 70 $\mathrm{eV}$ are shown in figure 2. While the fragmentation of the protonated molecule of Sparfloxacin using CI technique are shown in figure 4.

Electron ionization technique is the oldest and best characterized of all the ionization methods. In this technique, a beam of electrons passes through the gas-phase of the sample (Alison\& Neil 1997). Most mass spectrometers use electrons with energy of 70 electron volts $(\mathrm{eV})$ for recording mass spectra. Decreasing the electron energy can reduce the fragmentation processes, but it also reduces the number of ions formed (Alison\& Neil 1997). In this work, 70 and $15 \mathrm{eV}$ electron energies were used to study the fragmentation processes. The mass spectra of Sparfloxacin at these two energies are shown in Figures (2-3) in the range from $\mathrm{m} / \mathrm{z} 50$ to $\mathrm{m} / \mathrm{z} 450$.

Sparfloxacin molecule has a highly electronegative atoms O12 ($0.297 \mathrm{e})$ and $\mathrm{N} 1$ (-0.297 e) as shown in Fig. 6. From the calculated charge distributions at $\mathrm{N} 1$ and $\mathrm{O} 12$ in the qinolone ring of Sparfloxacin and the presence of lone pair electrons at these atoms, one can suggest that the ionization processes may occur at these atoms (Fig.1).

The calculated value of the ionization energy of Sparfloxacin is equal to $6.6 \mathrm{eV}$ (using equation 1).

IE $[\mathrm{M}]=\Delta \mathrm{H}_{\mathrm{f}}[\mathrm{M}]^{+\bullet}-\Delta \mathrm{H}_{\mathrm{f}}[\mathrm{M}]$

Where $\Delta \mathrm{H}_{\mathrm{f}}[\mathrm{M}]^{+\bullet}$ and $\Delta \mathrm{H}_{\mathrm{f}}[\mathrm{M}]$ are the heats of formation of the molecular ion and neutral molecule respectively. While electron affinity of sparfloxacin is equal to $9.97 \mathrm{eV}$ (using equation 2)

EA $[M]=\Delta H_{f}[M]-\Delta H_{f}[M]$

a) Fragmentation of Sparfloxacin using EI technique

The EI mass spectra of Sparfloxacin are recorded at both 15 and $70 \mathrm{eV}$ electron energies from $\mathrm{m} / \mathrm{z} 50$ up to $\mathrm{m} / \mathrm{z} 450$. The molecular ion of Sparfloxacin at $\mathrm{m} / \mathrm{z} 392$ is observed in the spectra at both $70 \mathrm{eV}$ and $15 \mathrm{eV}$ with relative intensities $20 \%$ and $100 \%$, respec- 
tively. From the mass spectra of Sparfloxacin at 70 and $15 \mathrm{eV}$ one, can note that the intensity of the molecular ion peak at 392 decrease with the increase of electron energy as shown as in figures 2,3 .

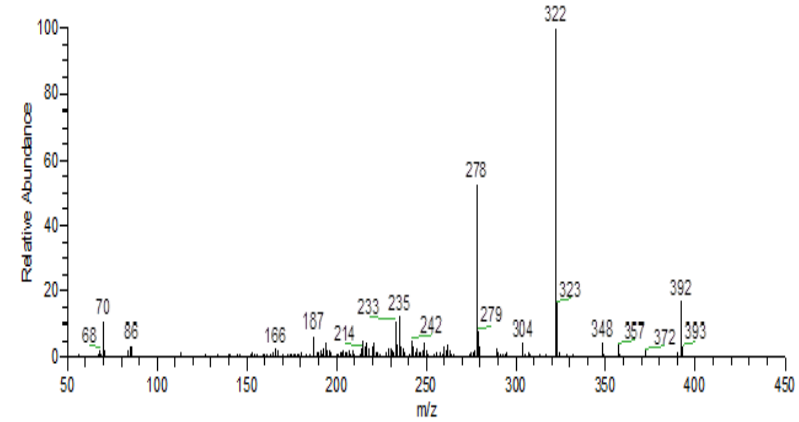

Fig. 2: Electron Ionization Mass Spectrum of Sparfloxacin at $70 \mathrm{E} \mathrm{V.}$

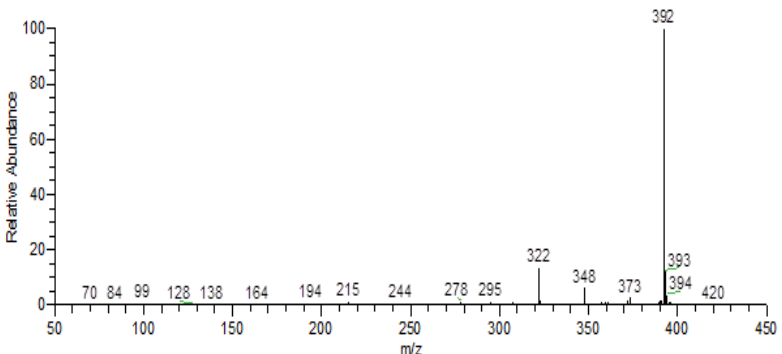

Fig. 3: Electron Ionization Mass Spectrum of Sparfloxacin at $15 \mathrm{E} \mathrm{V.}$

The first characteristic fragmentation pathway for Sparfloxacin is the formation of the fragment $\left[\mathrm{M}-\mathrm{C}_{4} \mathrm{H}_{8} \mathrm{~N}\right]^{+}$ion at $\mathrm{m} / \mathrm{z} 322$ (RI $=100 \%$ i.e. the base peak in the mass spectrum at $70 \mathrm{eV}$, while the intensity of this ion decrease to $15 \%$ at $15 \mathrm{eV}$ as shown as in figures 2,3). This ion is formed by the loss of $\mathrm{C}_{4} \mathrm{H}_{8} \mathrm{~N}^{*}$ radical from piperazinyl group. This is confirmed by the calculated bond length for $\mathrm{C} 15-\mathrm{C} 16$ and $\mathrm{C} 18-\mathrm{C} 19$ in charged molecular ion which are greater than that of the neutral molecule by $0.0005 \AA$ and $0.0008 \AA$, respectively (figs. 4-5). The fragment $\left[\mathrm{M}-\mathrm{C}_{4} \mathrm{H}_{8} \mathrm{~N}\right]^{+}$ion undergoes further fragmentation resulting in the formation of the fragment $\left[\mathrm{M}-\mathrm{C}_{4} \mathrm{H}_{8} \mathrm{~N}-\mathrm{CO}_{2}\right]^{+}$ion at $\mathrm{m} / \mathrm{z} 278(\mathrm{RI}=40 \%$ at $70 \mathrm{eV}$ and $5 \%$ at 15 $\mathrm{eV}$ ) by loss of $\mathrm{CO}_{2}$ from the carboxyl group attached to carbon $\mathrm{C} 3$ atom of the molecular ion as shown as in scheme 1 . This is confirmed by the calculated bond length for $\mathrm{C} 3-\mathrm{C} 9$ in the charged molecular ion which is greater than that of the neutral molecule by 0.0217 A.as shown as in figs. 4,5 .

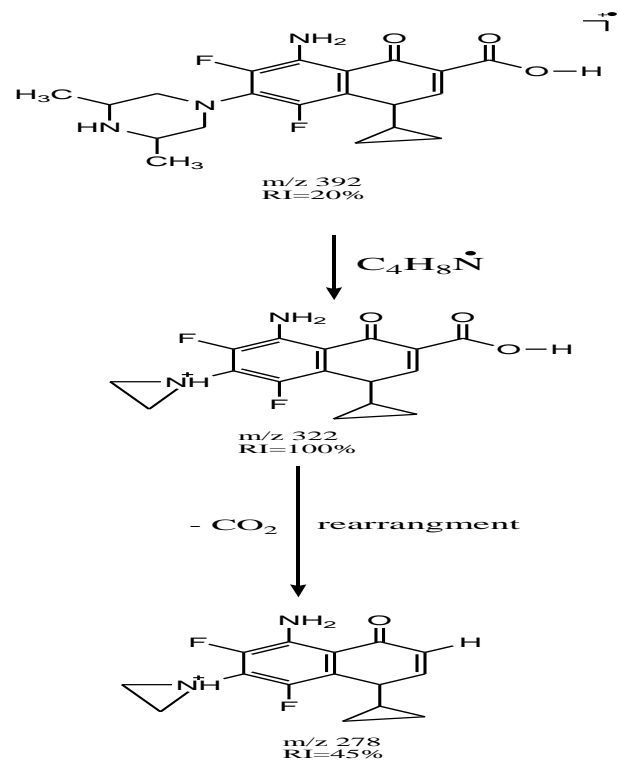

Scheme 1: Main Fragmentation Pathways of Sparfloxacin at 70 Ev.

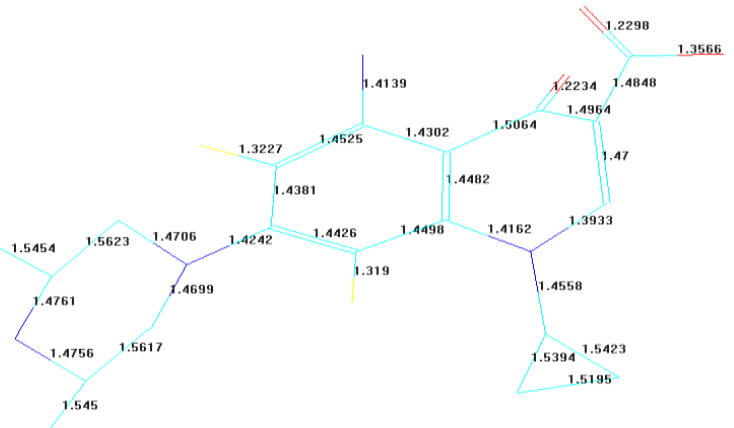

Fig. 4: The Bond Lengths of Sparafloxacin in Neutral State.

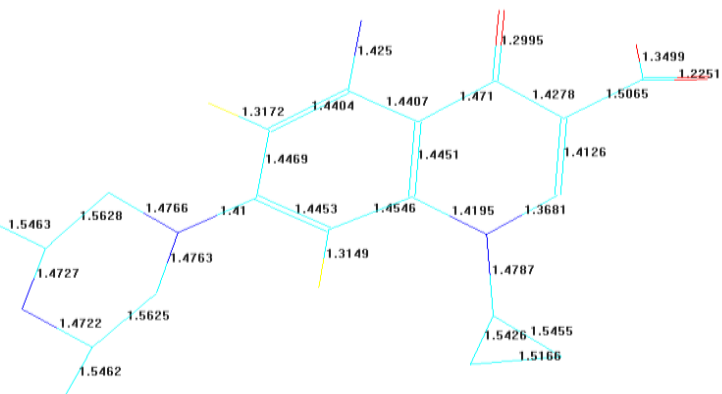

Fig. 5: The Bond Lengths of Sparafloxacin in Cation State.

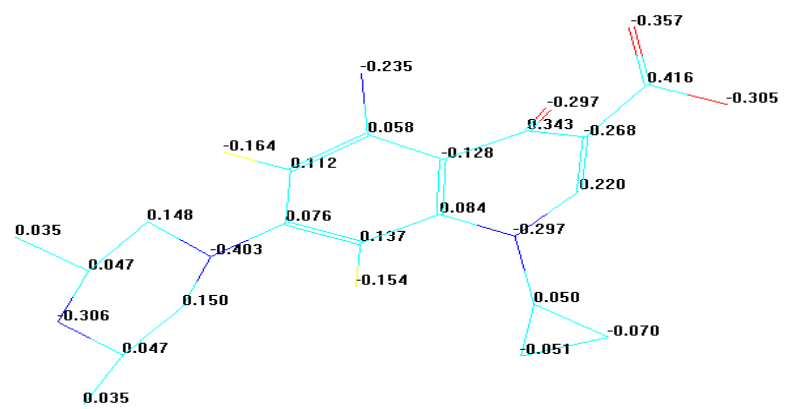

Fig. 6: The Charge Distributions of Neutral Sparfloxacin.

b) Fragmentation of Sparfloxacin using CI technique:

The chemical ionization (CI) technique is usually defined as a soft-ionization method. This means that the energy deposition into the molecule is thought to be less than that present in the electron ionization mode. This is reflected on the occurrence and / or on the yield of ions formed by fragmentation processes, which will be less than the fragments in EI method. Hence, the mass spectra of $\mathrm{CI}$ are much less complex than the EI spectra and few fragmentations are observed (Brian et al. 1991). An ion at $m / z=393$ is represent the protonated molecule $[\mathrm{M}+\mathrm{H}]^{+}$of Sparfloxacin and represent the base peak (R $\mathrm{I}=100 \%)$ in the CI mass spectrum of this molecule which indicate the high stability of the protonated molecule as shown as in figure 7 . This is an important advantage since this allows one to focus on the molecular ion.

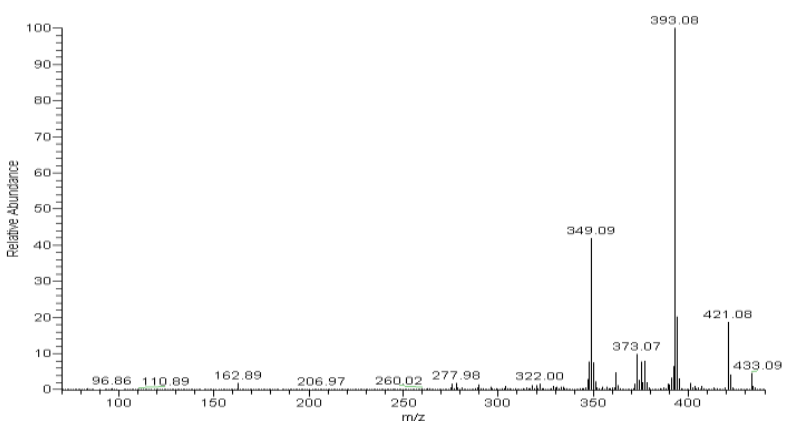

Fig. 7: Chemical Ionization Mass Spectrum of Sparfloxacin. 
The protonated molecule $[\mathrm{M}+\mathrm{H}]{ }^{+}$of Sparfloxacin undergoes fragmentation by the formation of the fragment $\left[\mathrm{MH}-\mathrm{CO}_{2}\right]^{+}$ion at $\mathrm{m} / \mathrm{z} 349$ (RI=45\%) which is formed by loss of $\mathrm{CO}_{2}$.

Two peaks observed at $\mathrm{m} / \mathrm{z} 421$ and 433 are probably formed due to the transfer processes of the $\left(\mathrm{C}_{2} \mathrm{H}_{5}\right)^{+}$and $\left(\mathrm{C}_{3} \mathrm{H}_{5}\right)^{+}$cations to form of $\left[\mathrm{M}+\mathrm{C}_{2} \mathrm{H}_{5}\right]^{+}$and $\left[\mathrm{M}+\mathrm{C}_{3} \mathrm{H}_{5}\right]^{+}$ions with unsaturated compounds with relative intensities 20 and $10 \%$, respectively as shown as in figure 7 . These adduct ions provide additional confirmation of the molecular weight of the compound (Munson 2000).
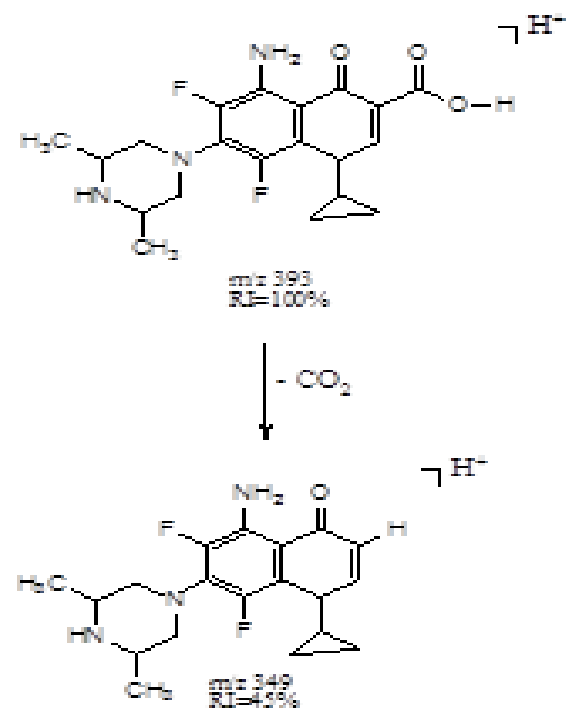

Scheme 2: Main Fragmentation Pathways of Protonated Sparfloxacin under CI Technique.

\subsection{Semi-empirical molecular orbital calculations of sparfloxacin}

The structure of our studied compound was optimized using MNDO (semi-empirical molecular orbital method) to report its thermochemical and energies data. The semi-empirical methods can be optimized for different purposes. For instance, MNDO method were used to calculate heats of formation and structures energies data of the studied compound in the gas phase as shown in Table 1. Authors have determined the values of heats of formation, total energies of the neutral, cation and anion molecule. Also, ionization energy and electron affinity have been calculated. These thermochemical data are important in the description of the conformational properties of the studied compound and are not published before as our knowledge.

Table 1: The Computed Thermochemical Properties of Sparfloxacin Using MNDO Method

\begin{tabular}{|c|c|c|c|}
\hline & Neutral & Cation & Anion \\
\hline Heat of formation $\Delta \mathrm{H}_{\mathrm{f}}(\mathrm{M})(\mathrm{kca}$ & -103 & - & - \\
\hline Heat of formation $\Delta \mathrm{H}_{\mathrm{f}}(\mathrm{M})^{+\bullet}\left(\mathrm{kcal} \cdot \mathrm{mol}^{-1}\right)$ & - & 50 & - \\
\hline $\mathrm{H}_{\mathrm{f}}(\mathrm{M})^{-}\left(\mathrm{kcal} \cdot \mathrm{mol}^{-1}\right)$ & - & - & -180 \\
\hline$\left(\mathrm{kcal} . \mathrm{mol}^{-1}\right)$ & -126666 & -126513 & -126742 \\
\hline Dipole moment (Deby) & 3.659 & 3.293 & 7.289 \\
\hline
\end{tabular}

From the calculated data of the studied molecule (Table 1), one can observed that the negative values of the heats of formation and total energy for neutral molecule are $-103,-126666$ kcal.mol-1 respectively indicating that this is a thermodynamically stable molecule. This may be due to the presence of quinolone ring (fig.1).

\section{Conclusion}

The experimental investigations show that the application of mass spectrometer can provide a rather detailed analysis of sparfloxacin by using a good obtained EI and CI mass spectra. These experi- mental data together with the theoretical quantum chemical calculations (MNDO) give us more information about the chemical behaviour of the studied molecules which may be important for many chemical and medical applications.

\section{References}

[1] Blondeau, J. M. (1999) Expanded activity and utility of the new fluoroquinolones: A review, Clinical Therapeutics. 21, 3-40 https://doi.org/10.1016/S0149-2918(00)88266-1.

[2] Stahlmann, R., Zippel, U., Förster, C., Schwabe, R., Shakibaei, M., Merker, H.J. and Borner, K. (1998) chondrotoxicity and toxicokinetics of sparfloxacin in juvenile rats, antimicrob. agents. Chemother, 42:6, 1470-1475.

[3] Singh, R. Pandey, V. K. and Srimal, R. C. (1992) synthesis of "1-2'(5'-alkyl-1', 3, 4'-thiadiazolyl)-2-methyl-4-(2"-phenyl-indole-3"yl)-methylene-imidazole-5-ones" as CVS, CNS and antiinflammatory agents. Indian J. Pharm. Sci, 54(1): 4-9.

[4] David, W. Henry in R.M. Acheson (Ed.), (1972) “ Heterocyclic Compounds"vol.9, p815, Interscience Publishers, New York.

[5] Libel, R., Randle, R., Mildenberger, H., Bauer, K. and Biernger H, (1988) Chen Abstr, 108(1), 6018.

[6] Menon, C.S., Robert, K.Y., Zee-Cheng and C. C. Cheng (1977) synthesis of dimethoxybenz $[\mathrm{g}]$ isoquinolines J. of Heterocyclic Chem.. 14,909-915.

[7] Christos, A., Alexandros, M., Zografos, L. and Olga, Igglessi-M. (2003) An Efficient Route to 3-aryl-aubstituted quinolin-2-one and 1, 8-naphthyridin-2-one derivatives of pharmaceutical interest. Org Chem., 68, 4567-4569. https://doi.org/10.1021/jo0340051.

[8] Jain, S., Jain, N.K. and Pitre, K.S. J.,(2002) Electrochemical analysis of sparfloxacin in pharmaceutical formulation and biochemical screening of its Co(II) complex, Pharm. Biomed Anal., 29,795-801. https://doi.org/10.1016/S0731-7085(02)00178-4.

[9] Marona, H.R.N. and Schapoval, E.E.S., (2001) Spectrophotometric determination of sparfloxacin in pharmaceutical formulations using bromothymol blue, J. Pharm. Biomed Anal., 26, 501-504. https://doi.org/10.1016/S0731-7085(01)00429-0.

[10] Faria, A.F., de Souza, M.V.N., de Almeida, M.V. and de Oliveira, M. A. L., (2006) Simultaneous separation of five fluoroquinolone antibiotics by capillary zone electrophoresis, Anal. Chim. Acta, 579, 185-192. https://doi.org/10.1016/j.aca.2006.07.037.

[11] Maronaab, H.R.N. and Schapoval, E.E.S. (1999) A highperformance liquid chromatographic assay for sparfloxacin, J. Pharm. Biomed Anal., 20, 413-417. https://doi.org/10.1016/S07317085(98)00102-2.

[12] Ziyu, P., Jingdong, P., Xu, Z. Huanjun, P., Huan, X., Lingli, B., Fang, C., Yan, H., Yu, C., Xiang, W., Shiyu, L. and Yi, Chen.,(2017) High performance liquid chromatography study of gatifloxacin and sparfloxacin using erythrosine as postcolumn resonance rayleigh scattering reagent and mechanism study, Luminescence.1-8.

[13] CaO,S.X.,Zhang,J.Y.andLiu,H.M.(2001) Quantitative analysis of sparfloxacin injection by high performance liquid chromatography, Chinese J. Chromatogr., 19, 454-456.

[14] Sun, S.W. and Wu, A.C. (1999) Determination of fluoroqinolone antibacterials in pharmaceutical formulations by capillary electrophoresis, J. Liq. Chromatogr. Relat. Technol., 22, 281-296. https://doi.org/10.1081/JLC-100101660.

[15] Fierrens, C., Hillaert, S. and Bossche, W.V. (2000) the qualitative and quantitative determination of quinolones of first and second generation by capillary electrophoresis, J. Pharm. Biomed. Anal., 22, 763-772. https://doi.org/10.1016/S0731-7085(99)00282-4.

[16] Askal, H., Refaat, I., Darwish, I. and Marzouq, M. (2007) Evaluation of N-Bromosuccinimide as a New Analytical Reagent for the Spectrophotometric Determination of Fluoroquinolone Antibiotics, Chem. Pharm. Bull., 55, 1551-1556. https://doi.org/10.1248/cpb.55.1551.

[17] El-Didamony, A. M. (2007) spectrophotometric setermination of sparfloxacin in pharmaceutical preparations by ternary complex formation with Pd (II) and eosin, Anal. Lett. , 40, 2708-2720. https://doi.org/10.1080/00032710701588408.

[18] Chowdary,K.P.R.andRao,G.D.(1997) spectrophotometric method for the determination of lomefloxacin hydrochloride, Indian drugs., 34, 107-110.

[19] Vegad, K. L., Dani, N.H., Shah, D. A., Patel, E.D., Patel, Y. K. and Patel. K. R. (2017) absorption correlation method for simutaneous estimation of sparfloxacin and dexamethasone in spard tablet dosage form, Pharma Science Monitor. 8 (3), 267-281. 
[20] Rizk, M., Belal, F., Ibrahim, F., Ahmed, S., and El-Enany. N. (2000) spectrofluorimetric analysis of certain 4-quinolone in pharmaceuticals and biological fluids, Pharmaceu. Acta Helvetiae., 74, 371-377. https://doi.org/10.1016/S0031-6865(00)00025-X.

[21] Du, L.M., Zhou, J., Xu, Q.Q., Fan, Z.F.,and Yuan, R.(2000) Study on fluorescence property of sparfloxacin derivatizing system and its applicationChin. Chem.Lett, 11, 255-258.

[22] Jasmin, S., Rasul Jan, M., Inayatullah, and Sultan, S.,(2012) Sensitive spectrofluorimetric and spectrophotometric methods for determination of sparfloxacin in pharmaceuticals, J. Mex. Chem. Soc. 256(2), 109-114

[23] Urszl K.K., Radosław, S., Katarzyna, G. R., Gabriela, B. P., Agnieszka,K. and Małgorzata, J.B.,(2015) Phosphine derivatives of sparfloxacin - Synthesis, structures and in vitro activity, J. Mol. Struct.,1096,55-63. https://doi.org/10.1016/j.molstruc.2015.04.044.

[24] Sultan, S.M., Alzamil, I.Z., Alrahman, A.M.A., Altamrah, S.A. and Asha, Y.(1986) Use of cerium(IV) sulphate in the spectrophotometric determination of paracetamol in pharmaceutical preparations, Analyst., 111, 919-921. https://doi.org/10.1039/an9861100919.

[25] Koukli, I.I., Calokerinos, A.C. and Hadjiioannou, T.P., (1989) Continuous-flow chemiluminescence determination of acetaminophen by reduction of cerium (IV), Analyst, 114, 711-714. https://doi.org/10.1039/an9891400711.

[26] Martínez Calatayud, J. and Garcia Mateo, V. (1992) Cerium (IV) arsenite as a solid-phase reactor for use in flow-injection analysis Spectrophotometric determination of promethazine, Anal. Chim. Acta, 264, 283-289. https://doi.org/10.1016/0003-2670(92)87016-E.

[27] Perez-Rinz, T., Martinez-Lozano, C., Tomas, V. and Sidrach de Cardona, C. (1993) Flow-injection fluorimetric determination of trimeprazine and trifluoperazine in pharmaceutical preparations $\mathrm{Ta}-$ lanta, 40, 1361-1365. https://doi.org/10.1016/0039-9140(93)802119.

[28] Alwarthan, A.A. (1995) Chemiluminescent determination of tryptophan in a flow injection system, Anal. Chim. Acta, 317, 233-237. https://doi.org/10.1016/0003-2670(95)00390-8

[29] Aly, F.A., Alarfaj, N.A. and Alwarthan, A.A. (1998) Flowinjection chemiluminometric determination of some phenothiazines in dosage forms and biological fluids, Anal. Chim. Acta, 358, 255262. https://doi.org/10.1016/S0003-2670(97)00622-3.

[30] Adegoke, O.A. and Balogun, B.B.(2010) Spectrophotometric determination of some Quinolones antibiotics following oxidation with cerium sulphate, Int. J. Pharm. Sci. Rev. Res.,4, 1-10.

[31] Mahendra, K., Trivedi, A. B., Dahryn, T., Harish, S., Khemraj, B. and Snehasis, J., (2015) fourier transform infrared and ultravioletVisible spectroscopic characterization of biofield treated salicylic acid and sparfloxacin, Nat.Prod. Chem. Res. 3(5), 1-6.

[32] W.Thiel, (2003) "Handbook of Molecular Physics and Quantum Chemistry" (Ed. S. Wilson), Bd. 2, Wiley, Chiceste, page 487.

[33] HyperChemTM, Release 7.5 Pro for Windows, "Molecular Modeling System", Hypercube, :User Evaluation copy, Organization: Evaluation copy, Dealer:Copyright@2002 Hypercube,Inc, Serial No.99-999-9999999999

[34] Alison, E. A., Neil, W. B.(1997) Ionization Methods in Organic Mass Spectrometry, Royal Society of Chemistry publisher; 1 edition (December 31, 1997) p.20. North Yorkshite, UK

[35] Brian, A.E.,Scott A.M. and Gary L.G.(1991) Comparison of electron ionization and chemical ionization sensitivities in an ion trap mass spectrometer, Int. J. Mass Spectrom. Ion Process, 106, 137 157 https://doi.org/10.1016/0168-1176(91)85015-E.

[36] Munson, B. (2000) Development of chemical ionization mass spectrometry, Int. J. Mass Spectrom.200, 243-251. https://doi.org/10.1016/S1387-3806(00)00301-8. 